\title{
HOW PHYSICIANS TREAT MENTALLY DISTRESSED MEN AND WOMEN
}

\author{
LOIS M. VERBRUGGE \\ 5005 Institute for Social Research. University of Michigan. P.O. Box 1248. Ann Arbor, MJ 48106, U.S.A.
}

\begin{abstract}
There is speculation that women receive different medical care than men because physicians have stereotyped views about women's symptoms and treatment preferences. This paper asks if men and women who visit physicians for mental distress receive comparable medical care and, if not. whether medical considerations or psychosocial ones explain the differences. Data are from a large national survey of ambulatory care visits in the United States. We find that women and men are equally, likely to report mental distress as their main problem to physicians. Physicians determine that distressed men have mental disorders more often than distressed women. On the whole, distressed men and women receive similar numbers of diagnostic services. therapeutic services and dispositions for follow-up care. The kinds of services and dispositions differ a little: women tend to receive limited examinations, blood pressure checks and drug prescriptions more often; men are more likely to have general examinations, medical counseling or no service at all. Women are retained for follow-up care with the same physician more often: men tend to be sent elsewhere for additional care or no follow-up plans at all are made for them. Sex differences in care are statistically smail (only $6 \%$ of the many comparisons are significant at $P<0.05$ ). But the significant differences highlight two points: when differential care occurs, it is in non psychiatrists offices and it usually shows women receiving more of a given service or disposition. Differential care for women and men can be due to medical factors (such as patient age, prior visit status, seriousness of problem) or psychosocial ones (such as patient requests, patient emotionality, physician sex bias). When we control for several medical factors, the significant sex differences persist. This suggests that the extra care distressed women sometimes receive from nonpsychiatrists is due to patient behavior or physician attitudes.
\end{abstract}

Do physicians hold stereotypic views of men and women patients which affect the medical care they provide? Women's health advocates assert that women receive biased care, especially during visits for mental distress and reproductive concerns. They suggest that physicians tend to attribute psychological problems too readily to women, discount women's physical symptoms as more minor than men's, provide cursory diagnostic services to women, prescribe drugs too freely to them and plan less appropriate follow-up care [1-4]. These concerns have been buttressed by anecdotal evidence from patients, but not by broader scientific evidence. To date, scientific research on physician sex bias is scant, and it does not consistently show sexual stereotypes or biased treatment.

This paper focuses on medical care given to mentally distressed men and women. Prior research on sex differences in mental health has emphasized the prevalence of mental problems in large populations and people's propensity to seek medical care for mental problems. The studies show that women have higher rates of neuroses, men have higher rates of personality disorders and there is no sex difference for

An earlier version of this paper was presented at the annual meeting of the Society for the Study of Social Problems. Toronto. August 1981. The author is Associate Research Scientist (Institute of Gerontology) and Faculty Associate (Institute for Social Research) at the University of Michigan. Richard Steiner assisted in the analysis design and computing. Janet Hankin and Ronald Kessler offered valuable comments. The analysis was supported by a research grant from Hoffmann-La Roche Inc.

$5.5 \times 181 \cdots$ psychoses [5]. Women tend to seek medical help for their emotional problems more than men [6]. Our interest is what happens at the physician's office once a person recognizes mental distress and seeks care for it. Do women patients present mental problems more often than men patients do ? Do distressed men and women report different kinds of symptoms? Do physicians give more diagnoses of mental disorder to women patients? Do troubled women receive fewer diagnostic services and less follow-up care, but more therapeutic services (especially drugs)? Do psychiatrists treat distressed men and women more equally than nonpsychiatrists do?

\section{DATA SOURCE}

The data source is the 1975 National Ambulatory Medical Care Survey (NAMCS). NAMCS is an ongoing survey of visits made to office-based physicians in the United States, conducted by the National Center for Health Statistics since 1973 [7]. Physicians in the following specialties are included: general and family practice, internal medicine, pediatrics, other medical specialties, general surgery, obstetrics and gynecology, other surgical specialties, psychiatry, other specialties. Osteopaths are included, but pathologists and radiologists are not. In 1975, 2472 physicians participated in NAMCS.

Sampled physicians keep special Patient Records for one week. The Record has information about a patient's sex, complaints, basic reasons for the visit (e.g. acute illness, postoperative care), diagnoses, medical services (both diagnostic and therapeutic), dispositions for follow-up care and several other items. The physician personally fills out all or most 
of the Record. A copy of the 1975 Patient Record is reproduced in Koch and McLemore [8].

This paper analyzes visits by adults $(18+$ years old) whose primary complaint or primary diagnosis was mental distress. Altogether, there are 1871 mental complaint visits (675 for men, 1196 for women) and 2505 mental diagnosis visits 1897 for men, 1608 for women)*. For simplicity, many statements here refer to 'men' and 'women'; but the true units of analysis are men's and women's visits.

The NAMCS Patient Record has space for three complaints and three diagnoses. Physicians are asked to note patient complaints at the beginning of the visit and diagnoses at the end of the visit. The principal complaint and principal diagnosis are listed first in each section, then any secondary complaints or diagnoses. Complaints are coded according to a Symptom Classification developed for NAMCS [9]. Mental Complaints have NAMCS codes 800-899; these include symptoms such as anxiety, depression, nervousness, fears and phobias, excessive drinking or smoking, nail biting and psychosexual disorders. Diagnoses are coded according to the International Classification of Diseases (ICD) [10]. Mental Diagnoses have ICD codes 290-315; they include conditions such as psychoses, neuroses, personality disorders, alcoholism, and drug dependence. We studied the two general groups (All Mental Complaints, All Mental Diagnoses), the three most common mental complaints (anxiely, depression, nervousness) and the three most common mental diagnoses (psychoses, neuroses, personality disorders). All results are for principal complaints and diagnoses unless stated otherwise.

\section{VARIABLES}

\section{Dependent variables}

The Patient Record has checkboxes for 18 services and 8 dispositions. (They are listed in Table 2 . Diagnostic services begin with 'Limited history/exam' and end with 'X-ray'; therapeutic services begin with 'Office surgery' and end with 'Psychotherapy/therapeutic listening'). In addition to the checkbox variables, we have created 6 summary indexes. They are: total number of services ordered or provided (NUMSERV), number of diagnostic services (NUMDIAG), number of therapeutic services (NUMTHER), total number of dispositions for further care (NUMDISP), extent of physical examination (EXAM; $\mathrm{O}=$ no exam, $\mathrm{l}=$ limited exam, 2 = general exam) and number of minutes spent with the physician (DURATION) $\dagger$.

*All numbers and results in this article are weighted so they reflect ambulatory visits for the 1975 U.S. population. Descriptive statistics here may differ slightly from those reported by the National Center for Health Statistics because we did additional 'cleaning' of the age and date of visit variables on the public-use tape.

tThe public-use tape shows duration as an ordinal variable with seven categories. For this analysis, we treated the variable as interval scaled by coding the midpoint minutes for each category.

\section{Independent variables}

These are 5 variables from the Patient Record that we take to be largely objective criteria in the physician's evaluation and decisions about care. They are: patient's age, seriousness of the complaint. prior tisit status, sick status (whether the patient is ill or injured or not) and basic reasons for the visit (acute problem, chronic problem, postoperative, other). Labels and coding rules for the variabies are as follows:

AGE Patient's age at last birthday, in years SERIOUS $1=$ not serious, 2 = slightly serious. $3=$ serious, $4=$ very serious

SEEN $\quad 1=$ new patient, $2=$ old patient treated for same problem before, $3=$ old patient presenting this problem for the first time

IFSICK $1=$ sick, 2 = not sick. 'Sick' is assigned if any diagnosis on the Record has an ICD code between 001-999. "Not sick' is assigned otherwise (all diagnoses have ICD codes between YOO-Y13) ( $Y$ codes are for examinations, skin sensitization tests, prenatal/postpartum care, plastic surgery, etc.)

TYPREAS The Patient Record has checkboxes for 14 reasons; the physician checks all relevant ones. From this information. we created a variable to distinguish acute problems, chronic problems. postoperative care and 'other' reasons. The variable also indicates if a combination of these reasons occurred. The categories are: acute problem only; chronic problem only; acute and chronic problems; postoperative only or postoperative and other; other only: acute and postoperative or acute and other; chronic and postoperative or chronic and other.

We refer to the independent variables as "medically relevant factors'. They are mainly determined by objective indications during the visit. (SERIOUS and IFSICK can involve subjective judgment too; we discuss this more later.) In this paper, we ask if men and women differ on the medically relevant factors and, if so, whether this explains any differences in care received by them.

\section{MENTAL COMPLAINTS PRESENTED BY WOMEN AND MEN}

Women and men are equally likely to present a mental problem as their principal complaint at a physician's office $(4.1 \%$ of women's visits, $4.0 \%$ of men's). Women, however, report them as secondary problems more often than men do (4.2 vs $3.0 \%$ for the second problem, 7.9 vs $7.1 \%$ for the third). As a result, women's visits are a bit more likely to involve mental distress than men's (5.4\% of all women's visit include a mental complaint vs $4.9 \%$ of men's).

Woman and men differ in the types of mental problems they bring to physicians: Women report more depression and more nervousness. Depression comprises $30.1 \%$ of their principal mental complaints 
vs. $19.0 \%$ for men; and nervousness, 29.1 vs $18.7 \%$. Men report more anxiety, psychosexual disorders and diffuse problems ("other symptoms or problems relating to mental health'). Anxiety comprises $13.3 \%$ of women's principal mental complaints vs $16.4 \%$ for men; psychosexual disorders, 1.5 vs $11.1 \%$; and diffuse problems, 17.2 vs $22.8 \%$.

Looking at all visits made by adults, mental complaints are much less common than physical ones. In the top-25 specific complaints, there is only one mental title for women (depression ranks 24 th and constitutes $1.2 \%$ of all women's visits), and none for men.

\section{MENTAL DIAGNOSIS GIVEN TO WOMEN AND MEN}

Women and men are equally likely to be diagnosed with a mental disorder as the principal diagnosis, by office-based physicians (5.4\% of women's visits, $5.4 \%$ of men's). But women tend to receive more secondary diagnoses of mental disorder (5.5 vs $4.1 \%$ for the second diagnosis, $8.6 \mathrm{vs} 8.0 \%$ for the third). This mirrors the fact that women report more mental distress as their secondary complaints. Overall, women's visits lead to mental diagnoses slightly more often than men's $(7.5 \%$ of all women's visits include a mental diagnosis vs $6.9 \%$ of men's).

The sexes differ sharply in the specific diagnoses they receive: Women get more diagnoses of neuroses, affective psychoses (such as manic-depression, melancholia) and vague mental disorders (special symptoms NEC, ICD code 306). Neuroses comprise $61.1 \%$ of women's principal mental diagnoses vs. $52.2 \%$ for men: affective psychoses, 4.3 vs $2.8 \%$; and vague mental disorders, 9.3 vs $4.7^{\circ}$. Men get more diagnoses of schizophrenia $\left(6.4,9.3^{\circ}\right)$, personality disorders $\left(7.0^{\circ} \%, 9.8 \%\right)$, alcoholism $\left(1.2 \%, 4.5^{\circ} \%\right)$, and vague psychosomatic disorders ("physical disorders of presumably psychogenic origin', ICD code 305, 3.1\%, $7.3 \%$ ). For psychoses in general (ICD 290-299), there is virtually no sex difference $(12.3 \%$ of women's mental diagnoses vs $13.4^{\circ}$ of men's).

These sex differences parallel those based on prevalence rates for large populations. Thus, for both the general community and office visits, neuroses are more common for women, personality disorders are more common for men, and psychoses show no sex difference.

Mental diagnoses are more common than mental complaints are. In the top-25 specific diagnoses, neuroses rank 5 th for both sexes $(3.3 \%$ of all women's visits, $2.8 \%$ of men's).

\section{THE MATCH BETWEEN COMPLAINTS AND DIAGNOSES}

When they complain of a mental problem, men are more likely to be diagnosed with a mental disorder than women are $\left(77.0^{\circ}\right.$ of all women's mental complaints vs $84.4 \%$ of men's). This appears for specific mental complaints too: anxiety, 90.6 vs $96.4 \%$; depression, 75.1 vs $79.0^{\circ}$ o: and nervousness, 59.7 vs $66.6 \%$. Possibly, men are reluctant to seek help for psychological and emotional problems. Those who ultimately do are very troubled and admit it to the physician, and physicians tend to agree with them. The data offer some support for this: Physicians evaluate men's mental complaints as more serious then women's $(40.0 \%$ of women's are very serious or serious vs $50.1 \%$ of men's).

By contrast, women seem more likely to report their physical problems in mental terms. When they complain of mental symptoms, they receive more physical illness diagnoses $(21.1 \%$ for women vs $14.3 \%$ for men). Thus, physicians disagree more with women about the etiology of their mental symptoms.

Women also seem more likely to report mental problems in physical terms. When they complain of physical symptoms, women get more diagnoses of mental disorder than men do. This appears for most kinds of complaints, but it is especially notable for nervous symptoms ( $18.1 \%$ of women's nervous complaints get mental diagnoses vs $13.5 \%$ of men's). (Examples of nervous symptoms are shaking, convulsions, headache, insomnia and vertigo/dizziness.)

In sum, men who complain of mental symptoms are more likely than women to receive a concurring diagnosis. More of women's mental symptoms receive physical diagnosis, and more of their physical symptoms receive mental diagnoses. Elsewhere, we have reported that women present a combination of physical and mental symptoms more often than men do [11]. All of this suggests a rather permeable boundary between physical and mental symptoms for women. Thus, physical illness may cause depression more readily for women; and anxiety may sensitize them to physical discomforts or even cause biochemical changes which induce physical symptoms more readily. But the first result may also reflect selectivity of men who bring mental problems to physicians. Mildly troubled men may avoid getting professional help; those who seek it are more likely to have a genuine mental disorder which is obvious and quite serious.

\section{VISITS TO PSYCHIATRISTS AND NONPSYCHIATRISTS}

Only about $3 \%$ of all ambulatory care visits are to psychiatrists (3.1\% for women, $3.5 \%$ for men). Most such visits involve mental complaints $(71.6 \%$ of women's, $72.8 \%$ of men's) and result in mental diagnoses $(91.3 \%, 91.9 \%)$. Anxiety and depression are common complaints treated by psychiatrists (Tablel). (Situational problems, fears and phobias, and psychosexual disorders also rank quite high.) The most common diagnoses given by psychiatrists are psychoses, neuroses, and personality disorders.

By contrast, mental complaints are uncommon for nonpsychiatrists $(1.8 \%$ of women's visits, $1.5 \%$ of men's). No mental complaint appears among the top-25 problems handled by them. Diagnoses of mental disorder are also uncommon, and they tend to be simple ones $(61 \%$ are neurosis). This focus on neurosis pushes it into the list of top-25 diagnoses (rank 7 for women, rank 16 for men).

Overall, psychiatrists are the principal helpers for complaints of anxiety and depression and for diagnoses of psychoses and personality disorders. However, they are infrequent helpers for the complaint of nervousness, and they handle only about half of all 
LOIS M. VERBRLGGE

Table 1. Mental complaints and diagnoses, by physician speciality and pattent sex*

\begin{tabular}{|c|c|c|c|c|c|c|}
\hline \multirow[b]{4}{*}{ Total no. of visits to } & \multicolumn{2}{|c|}{ No. of visits } & \multicolumn{2}{|c|}{$\begin{array}{l}\text { Percent of all } \\
\text { visits to this } \\
\text { specialty }\end{array}$} & \multicolumn{2}{|c|}{$\begin{array}{l}\text { Rank (in top } 25 \\
\text { specific complaints. } \\
\text { or specitic diagnoses) }\end{array}$} \\
\hline & Women & Men & Women & Men & Women & Men \\
\hline & \multicolumn{6}{|c|}{ Pstchialrists } \\
\hline & 927 & 593 & & & & \\
\hline Mental Complaints $t$ & 664 & 431 & 72 & 73 & & \\
\hline Anxiety & 116 & 88 & 13 & 15 & + & 3 \\
\hline Depression & 236 & 101 & 25 & 17 & 1 & 2 \\
\hline Nervousness & 33 & 17 & 4 & 3 & 6 & 7 \\
\hline Mental Diagnosest & 846 & 544 & 91 & 92 & & \\
\hline Psychoses & 155 & 105 & 17 & 18 & 2 & 2 \\
\hline Neuroses & 482 & 285 & 52 & 48 & l & $i$ \\
\hline \multirow[t]{2}{*}{ Personality Disorders } & 111 & 87 & 12 & 15 & 3 & 3 \\
\hline & \multicolumn{6}{|c|}{ Non psuchiarists } \\
\hline $\begin{array}{l}\text { Total no. of visits to } \\
\text { this specialty }\end{array}$ & 28,931 & 16,395 & & & & \\
\hline Mental Complaints & 532 & 244 & 2 & 1 & & \\
\hline Anxiety & 43 & 23 & 0 & 0 & - & $\ldots .$. \\
\hline Depression & 123 & 27 & 0 & 0 & - & $\ldots$ \\
\hline Nervousness & 314 & 110 & 1 & 1 & - & -- \\
\hline Mental diagnoses & 762 & 353 & 3 & 2 & & \\
\hline Psychoses & 42 & 15 & 0 & 0 & & $\cdots-$ \\
\hline Neuroses & 501 & 184 & 2 & 1 & $\rightarrow$ & 16 \\
\hline Personality Disorders & 1 & 1 & 0 & 0 & & $\ldots$ \\
\hline
\end{tabular}

Table 2. Services and dispositions given for mental distress. by physician specialty and patient sex*

\begin{tabular}{|c|c|c|c|c|c|c|c|c|}
\hline & \multicolumn{4}{|c|}{ All Mental Complaints } & \multicolumn{4}{|c|}{ All Mental Diagnoses } \\
\hline & \multicolumn{2}{|c|}{ Psychiatrists } & \multicolumn{2}{|c|}{ Nonpsychiatrists } & \multicolumn{2}{|c|}{ Psychiatrists } & \multicolumn{2}{|c|}{ Nonpsvchiatrists } \\
\hline Visits by: & Women & Men & Women & Men & Women & Men & Women & Men \\
\hline \multicolumn{9}{|l|}{ Services ( $\%$ of visits) } \\
\hline No services & 0.4 & 0.6 & 0.5 & 1.6 & 0.4 & 0.6 & 0.8 & 0.6 \\
\hline Limited history/examination & 3.2 & 1.9 & 51.6 & 42.8 & 2.9 & 2.8 & 52.6 & 50.2 \\
\hline General history/examination & 0.8 & 1.8 & 13.2 & 12.2 & 0.9 & 2.1 & 15.5 & 19.0 \\
\hline Lab test & 0.3 & 0.1 & 17.9 & 18.9 & 0.3 & 0.6 & 16.3 & 20.0 \\
\hline Blood pressure check & 2.5 & 1.4 & 49.4 & 39.2 & 2.1 & 1.2 & 52.2 & 42.9 \\
\hline EKG & 0.0 & 0.0 & 1.9 & 2.6 & 0.1 & 0.0 & 3.9 & 7.1 \\
\hline Hearing test & 0.0 & 0.0 & 0.4 & 0.5 & 0.0 & 0.0 & 2.4 & 2.0 \\
\hline Vision test & 0.0 & 0.0 & 0.4 & 0.3 & 0.0 & 0.0 & 2.9 & 1.0 \\
\hline Endoscopy & 0.0 & 0.0 & 0.9 & 0.7 & 0.0 & 0.0 & 0.8 & 0.8 \\
\hline$X$-ray & 0.4 & 0.1 & 3.1 & 3.7 & 0.3 & 0.2 & 5.7 & 5.9 \\
\hline Office surgery & 0.1 & 0.1 & 0.4 & 1.6 & 0.1 & 0.0 & 0.1 & 0.8 \\
\hline Drug prescription & 26.5 & 25.0 & 62.1 & 56.1 & 25.3 & 24.6 & 58.9 & 53.8 \\
\hline Injection & 1.3 & 1.4 & 20.6 & 22.3 & 1.1 & 1.1 & 20.5 & 20.3 \\
\hline Immunization/desensitization & 0.1 & 0.0 & 0.7 & 0.4 & 0.1 & 0.0 & 1.1 & 1.5 \\
\hline Physiotherapy & 0.3 & 0.3 & 0.8 & 0.8 & 0.3 & 0.4 & 2.9 & 1.7 \\
\hline Medical counscling & 4.9 & 6.1 & 19.0 & 19.6 & 5.8 & 6.9 & 21.8 & 20.4 \\
\hline \multicolumn{9}{|l|}{ Psychotherapy/therapeutic } \\
\hline listening & 92.7 & 91.4 & 23.2 & 22.2 & 93.2 & 91.0 & 24.7 & 15.6 \\
\hline Other service & 8.8 & 12.1 & 3.6 & 5.2 & 8.7 & 13.1 & 4.9 & 7.0 \\
\hline \multicolumn{9}{|l|}{ Dispositions ( $\%$ of visits) } \\
\hline No follow-up plans & 2.5 & 3.0 & 4.0 & 5.7 & 2.4 & 3.3 & 8.8 & 10.0 \\
\hline Appointment & 92.8 & 91.3 & 63.9 & 60.1 & 92.1 & 91.1 & 52.2 & 47.9 \\
\hline PRN & 7.1 & 6.0 & 27.8 & 25.0 & 8.1 & 5.9 & 34.5 & 34.5 \\
\hline Telephone & 3.6 & 3.1 & 3.9 & 3.7 & 4.3 & 2.9 & 4.6 & 4.3 \\
\hline Referral & 0.9 & 1.1 & 3.9 & 8.8 & 1.1 & 1.0 & 4.6 & 6.8 \\
\hline Return to referring physician & 0.1 & 0.4 & 0.2 & 0.2 & 0.1 & 0.4 & 0.5 & 0.4 \\
\hline Admit to hospital & 0.6 & 1.0 & 1.7 & 2.9 & 0.8 & 0.8 & 0.7 & 1.2 \\
\hline Other disposition & 0.2 & 0.3 & 0.5 & 1.1 & 0.3 & 0.4 & 0.4 & 1.5 \\
\hline \multicolumn{9}{|l|}{ Index variables } \\
\hline NUMSERV & 1.4 & 1.4 & 2.7 & 2.5 & 1.4 & 1.4 & 2.9 & 2.7 \\
\hline NUMDIAG & 0.1 & 0.1 & 2.2 & 1.9 & 0.1 & 0.1 & 2.4 & 2.4 \\
\hline NUMTHER & 1.3 & 1.4 & 1.3 & 1.3 & 1.3 & 1.4 & 1.4 & 1.2 \\
\hline NUMDISP & 1.0 & 1.0 & 1.0 & 1.0 & 1.1 & 1.0 & 1.0 & 1.0 \\
\hline EXAM & 0.1 & 0.1 & 0.8 & 0.7 & 0.1 & 0.1 & 0.8 & 0.9 \\
\hline DURATION (min) & 41 & 43 & 16 & 16 & 42 & 43 & 16 & 15 \\
\hline
\end{tabular}

0.0 No cases received this service or disposition.

*Data for specific titles (anxiety, depression, etc.) are available on request. 
neurosis visits. Thus, the most serious mental problems do tend to be treated by psychiatrists*.

\section{MEDICAL CARE PROVIDED TO DISTRESSED MEN AND WOMEN}

We have reviewed the services and dispositions given to distressed men and women for All Mental Complaints, All Mental Diagnoses and the six specific problems (Table 2). There are some consistent differences in medical care: distressed women tend to get more limited examinations, blood pressure checks and drug prescriptions. Distressed men are more likely to receive general examinations, medical counseling and 'other' services (e.g. brochures, medical information, informal conversation) and also to get no diagnostic or therapeutic service at all. With respect to follow-up care, women are retained by the physician more, getting more return appointements, requests to telephone and recommendations to return if needed (PRN). By contrast, men are more often sent elsewhere for care (referrals, hospitalization), or they receive no follow-up plans at all. Physicians spend slightly more time with distressed men than with distressed women. Overall, the number of services given to men and women is similar; so is the number of dispositions. In sum, care to distressed men and women sometimes differs in kind but not in amount. Sex differences are often larger for the variables showing that "women receive more care" than those showing that 'men recieve more care': this will be statistically confirmed shortly.

Sex differences in care are larger for visits to nonpsychiatrists than to psychiatristst. This is especially clear for anxiety, depression and psychoses (data not shown). Anxious women are much more likely to be examined, get their blood pressure checked and receive a drug prescription or injection compared to anxious men. Anxious women are given

*These results could also reflect differences in how physicians label distress. Nonpsychiatrists may prefer gentler terms such as 'nervousness' and 'neurosis' to sterner tcrms such as "anxiety' and 'psychosis'.

+ Psychiatrists and nonpsychiatrists typically offer different kinds of care to distressed patients: not surprisingly, psychiatrists focus on psychotherapy, plan further ap pointments, and spend more time with patients. Nonpsychiatrists perform more diagnostic procedures such as physical examinations. lab tests and blood pressure checks. and they offer more medical counseling, drug prescriptions and injections. Nonpsychiatrists schedule follow-up care less often. preferring to refer patients to other physicians (most likely psychiatrists) or asking them to return if they wish (PRN).

†This statement is based on correlations $(r)$ between independent and dependent variables. Correlations were computed for All Mental Complaints. All Mental Diagnoses. and the six specific problems studied here. There are some exceptions but the overall statement is correct. The same relationships appear for All Visits [12].

$\$$ This is the model for mental complaints. For mental diagnoses. IFSICK is deleted since all visits with mental diagnoses are automatically 'sick' ones. In the regressions. all dependent variables are treated as interval scaled. The independent variables are transformed into dummy variables. with the exception of AGE which remains interval scaled. a return appointment twice as often. By contrast, physicians given medical counsel and therapeutic listening to anxious men much more often than to women; and the men are referred elsewhere twice as often. A similar pattern appears for depression. Psychoses are an anomaly: men diagnosed as psychotic receive much more extensive care than comparable women. The case base for these visits is small, and we suspect the results are idiosyncratic, possibly due to clustering of visits in a few medical practices.

The results are sharpened when we look at them statistically: We regressed the dependent variables on patient sex, with the equation $Y=f[$ SEX]. The top panel of Table 3 shows results of 448 regressions ( 32 dependent variables $\times 14$ complaint or diagnosis titles).

The most striking feature of Table 3 is how few statistically significant differences appear-only 30 out of 448 possible, or $6 \%$. Thus, the sex differences described above are usually small from a statistical viewpoint. On the whole, distressed men and women are treated similarly.

Still, the significant differences that occur tell a clear story: First, nonpsychiatrists are responsible for differential care; of the 30 differences, 28 of them occur in visits to nonpsychiatrists. By contrast, psychiatrists are extremely equitable in the care they offer to distressed men and women. Second, the majority of differences show that distressed women receive more care. (The exception is for psychoses, as noted above.)

Are the sex differences in Table 3 based on sound medical factors, or do they reflect psychosocial ones such as physician sex bias? For example, do distressed women receive more examinations because they are older or presenting the problem for the first time or because physicians assume that exams will appease troublesome female clients? NAMCS data provide some clues:

Consider first how the medical care given to distressed patients is influenced by the independent variables: older patients, serious problems, new patients, old patients with new problems, 'sick' patients and acute problems generate more medical care than others (data not shown) $\ddagger$. Second, distressed men and women differ in these presenting characteristics: the women tend to be older, and they are more often old patients with new problems (Table 4). These characteristics encourage more care for the women. On the other hand, distressed men have more serious problems, and they are more often new patients, characteristics that would encourage more care for man. Virtually all distressed patients are considered 'sick' regardless of sex, and neither sex consistently has more acute problems. In sum, several factors act to boost medical care for distressed women, and several for men.

Do the medically relevant factors account for the different care that women and men sometimes receive (top panel, Table 3)? To assess this, we computed multiple regressions which control for the medically relevant factors. The regressions have this form: $\hat{Y}=f[A G E$, SERIOUS, SEEN, IFSICK, TYPREAS, SEX]\&. We are interested in the coefficient for SEX. How often do significant sex differences disappear when medical factors are con- 


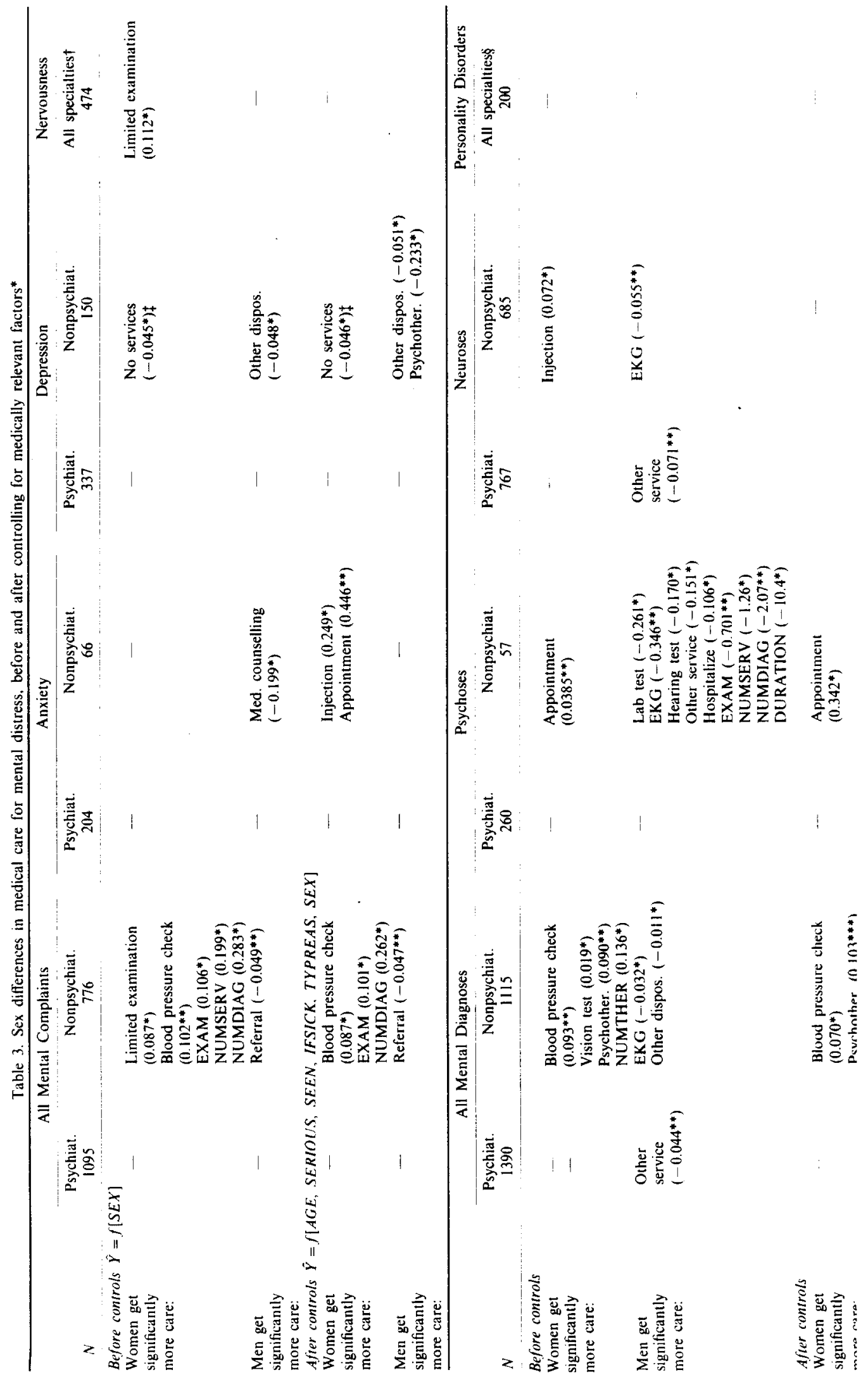


trolled? And do any new ones appear which were 'suppressed' at the outset? The bottom panel of Table 3 shows results of the 448 regressions.

Controlling for medically relevant factors does not help much. Only 12 of the 30 sex differences disappear (i.e. become nonsignificant), and 7 new ones appear. Altogether, we end up with 25 significant differences; this is a negligible improvement over the original 30 . If we look at the 448 initial differences (whether significant or not) and simply ask how many become smaller when controls are added, the result is similar: $44 \%$ of the differences do narrow but $32 \%$ widen. This again represents a small overall improvement.

The sex differences that persist or emerge repeat the earlier story: when significant differences in care occur, they are principally in visits to nonpsychiatrists and typically show more care for women patients. We could ponder the specific differences at the bottom on Table 3; for example, why do distressed men get more referrals even after some medical factors have been taken into account, or why are more diagnostic services performed for anxious women? But we caution readers that these specific differences may or may not appear in other data sets or even other years of NAMCS. The more important point is that sex differences in care are resistant to controls for medical factors.

This situation is not limited to mental distress. Elsewhere, we have reported that sex differences in medical care also persist for some common somatic complaints (fatigue, headache, vertigo/dizziness, chest pain, back pain) and for major complaint groups (digestive, cardiovascular, muscle/bone, etc.) $[12,13]$.

If the medical factors we have included do not reduce sex differences much, then what causes them? First, some important medical factors may still be missing in our analysis. Age, seriousness, prior visit status, sick status and acute vs chronic nature of problem are indeed important medical considerations, but they are not the only ones. Second, psychosocial factors may guide physicians to give differential care to distressed men and women. Do the women tend to ask for more services or more follow-up care with the same physician? Are the women visibly more distraught, prompting physicians to offer more assistance to them? Do physicians have stereotyped views of distressed women which influence the services and dispositions they choose for them? NAMCS data do not let us test these alternative hypotheses. But it is important to recognize that some medical factors may be absent, and that psychosocial factors can stem from patient behavior during office visits as well as from physician attitudes.

Some readers may also argue that the medically relevant factors in NAMCS are not 'clean'; i.e. that the evaluations of seriousness and sick status are not based solely on medical knowledge and expertise but can also involve subjective judgment. Distressed men are felt to have more serious problems than distressed women, and they are more often considered 'sick' (for depression and nervousness). If physicians tend to discount women's distress, this could partly explain why they say women have less serious problems and why they occasionally label them 'not sick'. We cannot determine if the sex differences in SERIOUS 
Table 4. Independent variables by patient sex and physician specialty, for mental distress visits ${ }^{\dagger}$

\begin{tabular}{|c|c|c|c|c|c|c|c|c|c|c|c|c|c|}
\hline & \multirow[b]{3}{*}{ Visits by: } & \multicolumn{6}{|c|}{ All Mental Complaints } & \multicolumn{6}{|c|}{ All Mental Diagnoses } \\
\hline & & \multicolumn{3}{|c|}{ Psychiatrists } & \multicolumn{3}{|c|}{ Nonpsychiatrists } & \multicolumn{3}{|c|}{ Psychiatrists } & \multicolumn{3}{|c|}{ Nonpsychiatrists } \\
\hline & & Women & Men & & Women & Men & & Women & Men & & Women & Men & \\
\hline Age (average) & & 37.5 & 36.9 & NS & 47.4 & 47.7 & NS & 37.3 & 36.9 & NS & 46.5 & 44.1 & * \\
\hline \multicolumn{14}{|l|}{$\begin{array}{l}\text { Seriousness of } \\
\text { complaint }\left({ }^{(*}\right)\end{array}$} \\
\hline Not serious & & 8 & 7 & NS & 40 & 32 & * & 9 & 6 & NS & 54 & 41 & $* *$ \\
\hline Slightly serious & & 27 & 25 & & 40 & 41 & & 28 & 25 & & 32 & 38 & \\
\hline Serious & & 53 & 54 & & 16 & 23 & & 51 & 56 & & 12 & 19 & \\
\hline Very serious & & 12 & 14 & & 4 & 4 & & 12 & 13 & & 2 & 2 & \\
\hline \multicolumn{14}{|l|}{ Prior visit status $\left({ }^{0}\right)$} \\
\hline New patient & & 4 & 4 & NS & 7 & 10 & NS & 4 & 5 & NS & 14 & 22 & $*$ \\
\hline Old patient with & & 94 & 95 & & 75 & 78 & & 93 & 93 & & 63 & 60 & \\
\hline old problem & & 2 & l & & 18 & 12 & & 3 & 2 & & 23 & 18 & \\
\hline \multirow{2}{*}{\multicolumn{14}{|c|}{$\begin{array}{l}\text { Old patient with } \\
\text { new problem }\end{array}$}} \\
\hline \multicolumn{8}{|l|}{ Sick status $\left({ }^{0}{ }_{10}\right)$} & & & & & & \\
\hline 'Sick' (ill or injured) & & 99.6 & 99.7 & NS & 93.3 & 94.8 & NS & $--^{+}$ & - & & - & & \\
\hline 'Not sick' & & 0.4 & 0.3 & & 6.7 & 5.2 & & & & & & & \\
\hline \multicolumn{14}{|l|}{ Reasons for visit $(0)$} \\
\hline Acute problem only & & 13 & 7 & * & 20 & 24 & NS & 12 & 7 & VS & 25 & 29 & NS \\
\hline Chronic problem only & & 32 & 35 & & 55 & 50 & & 32 & 32 & & $5 !$ & 48 & \\
\hline Acute and chronic problems & & 2 & 2 & & 3 & 2 & & 2 & 2 & & 2 & 2 & \\
\hline \multicolumn{14}{|l|}{ Postoperative only, } \\
\hline or postop and other\$ & & 0 & 0 & & 0 & 1 & & 0 & 0 & & 0 & 0 & \\
\hline Other onlys & & 24 & 24 & & 7 & 11 & & 22 & 25 & & 8 & 9 & \\
\hline $\begin{array}{l}\text { Acute and postop., } \\
\text { or acute and other }\end{array}$ & & 8 & 6 & & 5 & 4 & & 8 & 7 & & 6 & 4 & \\
\hline $\begin{array}{l}\text { Chronic and postop., } \\
\text { or chronic and other }\end{array}$ & & 21 & 26 & & 10 & 8 & & 24 & 27 & & 8 & 8 & \\
\hline
\end{tabular}

0 Less than $1 \%$

$* P<0.05 * * P<0.01$. NS means not significant $(P \geqslant 0.05)$. Based on 1 -test or Chi-square, as appropriate.

tData for specific titles (anxiety, depression. etc.) are available on request.

+ All visits with a mental diagnosis are 'sick' (ill or injured) visits.

$\$$ Other includes prenatal care, postnatal care, well-adult exam, family planning, counseling/advice. immunization. referred by other physician/agency, administrative purpose, other.

and IFSICK include such psychosocial aspects. Fortunately, this does not affect our conclusions, since the control variables failed to eliminate sex differences in care. (If they did so, we could not be sure that medical factors were entirely responsible.)

How can the importance of medical vs psychosocial factors be tested? Our approach has been to test some medical factors explicitly. The NAMCS data have no information about patient requests, patient emotionality or physician attitudes. By contrast, several other researchers have looked at psychosocial factors: first, Wallen et al. find that the information content of women's conversations with physicians differs from men's conversations with them [14]. Second, evidence on physician sex bias is mixed: McCranie et al. study sex stereotypes and find that physicians do not attribute women's symptoms to psychological problems more than men's [15]. But Bernstein and Kane report that physicians think women have more psychosomatic illnesses (physical problems triggered by emotional ones), and also think that emotional factors are more important in women's complaints [16]. They find that physicians feel similarly helpful to men and women who express an emotional problem; but in the absence of an emotional problem, they view women as more demanding and consider women's problems more psychosomatic. Third, Broverman et al. have shown that physicians' images of mental health for women and men differ, but whether these attitudes influence diagnosis and care is not studied [17]. In sum, research on psychosocial factors which might explain differential care has been sparse, and it is mostly limited to finding differences in physicians attitudes rather than to demonstrating how such attitudes affect physicians' care of men and women.

\section{SUMMARY AND CONCLUSION}

The main findings of this analysis are:

(1) Office visits focus on mental complaints and mental diagnoses equally often for women and men. As secondary problems, they are slightly more common for women.

Because women make more office visits than men do, physicians see notably more distressed women during a ycar than distressed men. (See the sample sizes in Table 1.) But on any given visit, a woman patient is only slightly more likely than a man patient to present a mental symptom or to receive a mental diagnosis

(2) The boundary between physical and mental problems is less clear for women than for men. Women appear to describe their physical ailments in mental terms more often, and also their mental problems in physical terms. In other words, they tend to 'phychologize' physical ailments and to 'somaticize' phychological ones. Other evidence of the first tendency is in Refs [11, 18].

(3) When men report mental troubles, physicians concur by giving mental disorder diagnoses more so than for women. This occurs whether men visit psychiatrists or nonpsychiatrists. Does this reflect reluctance by men to seek care for emotional prob- 
lems, so the men who finally do go are obviously troubled? Evidence of such reluctance is in [6]

(4) On the whole, distressed women and men are treated similarly. Usually (in $9 \%$ of the statistical comparisons), women and men receive comparable medical care. (We do see some tendency for women to receive more limited exams, blood pressure checks, and drug prescriptions; and men more general exams, medical counseling, 'other' services and no services. Also, women tend to get more follow-up care from the same physician, while men are sent elsewhere for further care or get no follow-up plans. Although these differences appear regularly, they are not especially large and few are statistically significant.)

When significant $(P<0.05)$ differences do occur, they reveal two points: first, differential care occurs in nonpsychiatrists ' offices; psychiatrists treat their distressed men and women clients very equally. Second, differential care usually shows women receiving more of a particular service or disposition than men.

The differential care cannot be explained by medical factors: we have controlled for patient age, seriousness of the complaint, prior visit status, sick status and reasons for visit. Because these affect medical care and also differ somewhat by sex, they could account for differential care. But most of the original sex differences persist. and some new ones even appear. The specific services and dispositions showing sex differences change a bit (compare the upper and lower panels of Table 3 ). But the overall situation remains the same-showing more care for women, almost solely by nonpsychiatrists. the reasons for this could still be medical if we have failed to include important medical considerations that differ by patient sex. but they are more likely psychosocial. We have discussed plausible psychosocial factors: if distressed women ask for more care or if they are more upset emotionally during the office visit, they may prompt physicians to provide more care. Or physicians may think that distressed women are gullible and fussy, prompting them to offer unnecessary services and dispositions.

Note that some psychosocial factors originate with the patients in their behavior during office visits. Physician responses to patient requests and emotions can be entirely appropriate and unbiased, focusing on each patient's needs regardless of sex. Other psychosocial factors orginate with physician attitudes about men in general and women in general. Care which is based on such attitudes is 'sex biased'.

This analysis should allay concerns that distressed men and women are treated in very different ways by physicians. We do not find that distressed women routinely receive fewer diagnostic services. more therapeutic ones or less follow-up care. (Instead, we find that they occasionally receive more diagnostic care, more therapeutic care, and more follow-up plans with the same physician.) We hope this analysis will inspire more scientific work on sex differentials in medical care. There are some important and often difficult questions to answer: how often do patients request particular services and dispositons, and do physicians comply with those requests? How do communication factors such as a patient's description of symptoms (elaborate vs cursory) or a patient's emotionality influence behavior? Do men and women differ in these verbal and nonverbal aspects? Where does 'sex bias' exist in medical practice; is it more prevalent for certain specialties or certain complaints? Do stereotypic attitudes about men and women patients actually lead to differential ('biased') care? How much can differential care of men and women be attributed to medical factors versus psychosocial ones stemming form patients or physicians? The NAMCS analysis shows that differential care to distressed women and men is not common, but where it occurs it is probably due to psychosocial factors rather than medical ones.

\section{REFERENCES}

1. Corea G. The Hidden Malpractice: How American Medicine Treats Women as Patients and Professionals. William Morrow, New York. 1977.

2. Ehrenreich B. Gender and objectivity in medicine. Int. J. Hlth Sert. 4, 617, 1974

3. Fidell L. S. 'Sex role stereotypes and the American physician. Psychol. Women Q. 4, 313-1980.

4. Schiefelbein S. The female patient-Heeded? hustled? healed? Saturday Review 29 March, 12, 1980.

5. Dohrenwend B. P. and Dohrenwend B. S. Sex differences and psychiatric disorders. Am. J. Saciol 81, $1447,1976$.

6. Kessler R. C., Brown R. L. and Broman C. L. Sex differences in psychiatric help-seeking: evidence from four large-scale surveys. J. Hlth soc. Behav. 22, 49, 1981

7. Tenney J. B., White K. L. and Williamson J. W. National Ambulatory Medical Care Survey: Background and Methodology. Vital and Health Statistics. Series 2, No. 61. National Center for Health Statistics, Rockville, MD, 1974.

8. Koch $\mathrm{H}$. and McLemore T. The National Ambulatory Medical Care Survey: 1975 Summary. Vital and Health Statistics, Series 13, No. 33. National Center for Health Statistics, Hyattsville, MD, 1978.

9. Meads S. and McLemore T. The National Ambulatory Medical Care Survey: Symptom Classification. Vital and Health Statistics, Series 2, No. 63. National Center for Health Statistics, Rockville, MD, 1974.

10. National Center for Health Statistics. Eighth Revision International Classification of Disease, Adapted for Use in the United States. PHS Pub. No. 1693. U.S. Government Printing office, Washington, D.C.

11. Verbrugge L. M. Sex differences in complaints and diagnoses. J. Behar. Med. 3, 327, 1980.

12. Verbrugge L. M. and Steiner R. P. Physician treatment of men and women patients-Sex bias or appropriate care? Med. Care 19, 609, 1981.

13. Verbrugge L. M. and Steiner R. P. Another look at physicians' treatment of men and women with common complaints. Forthcoming, Sex Roles.

14. Wallen J.. Waitzkin H. and Stoeckle J. D. Physician stcreotypes about female health and illness: a study of patient's sex and the informative process during medical interviews. Women Hlth 4, 135, 1979.

15. McCranie E. W. Horowitz A. J. and Martin R. M. Alleged sex-role stereotyping in the assessment of women's physical complaints: a study of general practitioners. Soc. Sci. Med. 12, 111, 1978.

16. Bernstein B. and Kane R. Physicians' attitudes toward female patients. Med. Care 19, 600, 1981

17. Broverman I. K., Broverman D. M and Clarkson F. E Sex-role stereotypes and clinical judgements of mental health. J. consult clin. Pslchol. 34, 1. 1970.

18. Phillips D. L. and Segal B. E. Sexual status and psychiatric symptoms. Am. sociol. Rer. 34, 58. 1969. 